\title{
Psychological support and counselling for patients with acquired immune deficiency syndrome (AIDS)
}

\author{
D MILLER AND J GREEN \\ Department of Clinical Psychology, St Mary's Hospital, London
}

SUMMARY The growing numbers of patients with the acquired immune deficiency syndrome (AIDS) in England has led to the development of a counselling service for patients, their sexual partners, contacts, and others. The nature of the counselling is described with reference to the primary qualitative issues arising from diagnosis. The necessity for preventative education for patients and those at risk is stressed, and guidelines for low risk sexual activities are outlined.

\section{Introduction}

From time to time a new disease appears that causes particular difficulties for the clinician. The recognition of the acquired immune deficiency syndrome (AIDS) in 1979 and its subsequent rapid spread is such a case. ${ }^{1}$ The AIDS problem in the United Kingdom is on a much smaller scale than in America. By November 198488 cases had been confirmed in the United Kingdom, as opposed to over 6000 cases in the United States. None the less, the numbers can be expected to rise on the basis of the American experience.

It now seems clear that AIDS is caused by a retrovirus. ${ }^{2}$ The appearance of the syndrome is the final stage of a complex process that starts with infection with the AIDS virus and is then probably exacerbated by subsequent infections, which result in irreversible immunosuppression. ${ }^{3}$

Recent evidence has shown that the retrovirus, human T lymphotropic virus type III (HTLV-III), which is responsible for AIDS, is already widespread in some sections of the homosexual community. ${ }^{4}$ Over $70 \%$ of AIDS sufferers in the United States are homosexual men, and there seems to be little doubt that some characteristics of their lifestyle put them at particular risk of acquiring AIDS and many other sexually transmitted diseases. Homosexual men tend to have large numbers of sexual partners. ${ }^{5} \mathrm{~A}$ study at the Centers of Disease Control (CDC) in America showed that controls had an average of 30 new partners a year, whereas patients with AIDS had had

Address for reprints: Dr D Miller, Department of Clinical Psychology, Paterson Wing, St Mary's Hospital, Praed Street, London W2 INY

Accepted for publication 19 November 1984
60 partners. ${ }^{6}$ Naturally, many of the sexual partners of highly sexually active homosexual men are casual contacts, the state of whose health is not known.

The specific sexual practices of homosexual men also seem to put them at risk of acquiring AIDS. The CDC case control study showed evidence that anal intercourse, particularly in the passive role, presents a higher risk of contracting AIDS. ${ }^{6}$ This parallels findings for other sexually transmitted diseases. ${ }^{7}$ The risk of tearing the rectal mucosa, and hence exposure to blood, may be the key factors. There are also growing suggestions that frequent swallowing of semen results in immune suppression, and large amounts of cytomegalovirus (CMV) in urine and semen indicate that frequent exposure to each substantially increases the risk of contracting opportunistic infection.

Men presenting at the Praed Street special clinic at this hospital who are diagnosed as having AIDS, and their lovers, are offered the opportunity of counselling. This offer has been extended recently to some men suffering from persistent generalised lymphadenopathy (PGL) and to those who have been found to have HTLV-III. Although it is too early to say what the take up rate for counselling is in these two groups, among patients with AIDS it has been high, with most taking up the opportunity. These men have been seen individually and in a support group run in cooperation with the Terence Higgins Trust, which provides "buddies" (companions who visit patients with AIDS and provide some degree of practical and emotional support) for such patients in London.

The patients already seen have presented a number of counselling issues for those working with homosexual men. These issues fall into four groups: (1) counselling men who have already got AIDS; (2) 
counselling the established lovers of patients with AIDS; (3) counselling patients with persistent generalised lymphadenopathy and those who give HTLV-III positive results; and (4) counselling homosexual men who are afraid that they have AIDS, although diagnostic indicators are absent.

\section{Counselling problems}

There are a number of practical problems in counselling patients with AIDS. The course of the confirmed illness cannot always be predicted. The prognosis for those with Pneumocystis carinii pneumonia is bleak (about $100 \%$ fatality rate after two years), whereas those with Kaposi's sarcoma may continue life more or less unaffected for a considerable period.

In lovers and sexual contacts of patients with AIDS, current immunological tests to screen for the AIDS retrovirus are sometimes difficult to interpret. Having the virus may not necessarily eventually lead to AIDS, and some men who are HTLV-III positive may possibly be immune to the virus. The long incubation period of the virus also creates much difficulty, particularly in those developing clinical anxiety and depression while "waiting for the worst". Men who have been in contact with the virus tend to ask how long it will be before they are "safe", and from current knowledge it is simply impossible to give a firm answer to this question.

\section{Counselling patients with AIDS}

The counselling of AIDS sufferers differs somewhat from that of other patients with potentially fatal diseases. The retrovirus is transmissible, so it is vital that the AIDS sufferer should be clearly aware of both the diagnosis and the details of his condition. It is important to be realistic about the fatality rate in patients with AIDS. By the end of three years over $70 \%$ of sufferers will be dead. At the same time there is an appreciable margin of hope for patients, and they should not be denied this.

It is important to ensure that the AIDS sufferer gives up all sexual contact, perhaps with the exception of an established monogamous partner. He must be made aware of, and encouraged to adopt, guidelines for sexual behaviour that avoid the risk of subsequent infections (see table I). Sexually transmitted diseases clearly may be much more serious in the context of existing immunosuppression. Celibacy also helps to ensure that the virus will not be transmitted to another person.

AIDS sufferers should also communicate the facts about the syndrome and their own diagnosis to those who are close to them. There is considerable fear and

\section{TABLE I Guidelines for safer sexual activity}

Patients with AIDS:

1. Maintain sexual activity only with established stable partner.

2. Inform established partner of the necessity for fidelity.

3. No anal intercourse (active or passive).

4. No oroanal sexual activity.

5. No orogenital sexual activity or exposure to partner's urine.

6. No "wet" kissing.

7. Keep only to (mutual) masturbation, body rubbing, and "dry" kissing.

Established lovers of patients with AIDS:

1. No anal intercourse (active or passive).

2. No oroanal sexual activity.

3. No orogenital sexual activity or exposure to partner's urine.

4. No "wet" kissing.

5. No new partners.

6. Keep only to (mutual) masturbation, body rubbing, and "dry" kissing.

7. Regular venereological screenings and prompt treatment of infections.

Contacts patients infected with HTLV-III virus, and patients with PGL:

1. Restrict sexual activity to known (preferably only one existing) partner.

2. No anal sexual activity (active or passive).

3. No oroanal sexual activity.

4. No orogenital sexual activity, or exposure to partner's urine.

5. No "wet" kissing.

6. Keep only to (mutual) masturbation, body rubbing, and "dry" kissing.

7. No new partners.

8. Regular venereological screenings and prompt treatment of infections.

Others:

1. Restrict sexual activity to known (preferably one only) partner, or to a closed circle of contacts.

2. No anal intercourse (active or passive).

3. No oroanal or orogenital sexual activity, or exposure to urine

4. No "wet" kissing.

5. Keep only to (mutual) masturbation, body rubbing, and "dry" kissing.

6. No sexual activity with people from high risk areas (America, Africa, Haiti).

7. Prompt treatment of venereological infections.

HTLV-III = human T lymphotropic virus type III

$\mathrm{PGL}=$ persistent generalised lymphodenopathy.

ignorance about the syndrome, and others need to understand what risks the AIDS sufferer presents to them and, more important, what risks he does not present. Many people in the community are afraid that AIDS can be transmitted easily by non-sexual means, perhaps by cups or by lavatory seats, and need to be reassured that transmission by such routes is not worth worrying about. On the other hand, exposure to blood and faeces from an infected person may present some real risk, and relatives, sexual partners, and friends need sensible advice on avoiding risk.

Telling others that he has the syndrome is often a source of great anxiety for the AIDS sufferer. Our patients report very mixed responses from friends and families. Generally friends have turned out to be unexpectedly supportive. A few friends, however, especially sexual contacts, respond by refusing to have anything more to do with the AIDS sufferer. The situation is often complicated by the fact that the 
families of some patients with AIDS are not aware that the men are homosexual. Telling their families that they have AIDS thus also means telling them that they are homosexual. Men often need specific advice on how to tackle telling others about their condition.

The AIDS sufferer also needs advice on ways of dealing with his own diagnosis. First, he needs to be helped to come to terms with the diagnosis, both intellectually and emotionally. He may have questions about his diagnosis that need to be answered in a straightforward, frank way. This is absolutely essential to proper, effective counselling.

Kubler-Ross has set out a widely accepted pattern of response to learning that one has a potentially fatal disease. ${ }^{8}$ The stages are: denial and isolation, anger, bargaining, depression, and acceptance. It is thought that all patients are likely to pass through all the stages. The picture seen by us in patients with AIDS has, however, been much more variable. There is no sign that all patients with AIDS necessarily pass through all these stages. Table II shows the themes that patients with AIDS, their lovers and contacts, and those with PGL have raised.

The first stage in counselling is to provide honest and unforced discussion of AIDS. Patients usually have many practical concerns about the syndrome, particularly what AIDS is, how they caught it, the likely prognosis, and the likely risk that they offer to others and that others offer to them. Some of their questions, particularly those about prognosis, cannot be answered, but an explanation of why they cannot be answered is acceptable to patients. It is clearly important that anyone engaging in counselling a patient with AIDS should have close contact with the physician in charge of the patient's case so that they can provide accurate answers to questions.

Having answered practical questions it is important that counsellors move on to a full assessment of how the patient is reacting to the diagnosis. Table II shows some of the common responses of patients to the diagnosis. The patient needs to be allowed to talk at some length about his reactions. It is also helpful for the counsellor to follow up the patient's description of his current state by probing gently for some of the themes illustrated in table II.

Once a clear picture of the patient's reactions has been built up and practical questions have been answered, the next task for the clinician is to assist the patient in regaining a feeling of control over his own life. Not only the diagnosis itself, but the changes it implies, and the actions of doctors investigating and treating the patient, can conspire to take away this feeling.

It may be that the patient will not die, but even if
TABLE II Qualitative issues in counselling related to AIDS

Patients with AIDS:

1. Shock of diagnosis and facing possible death.

2. Feeling of powerlessness to change circumstances, and consequent frustration and anger.

3. Reduced physical functioning because of declining health

4. Anxiety about the reactions of others, with consequent social withdrawal and loss of social support.

5. Reduced cognitive functioning because of anxiety, depression, obsessional worries, and possible intellectual impairment.

6. Reduced sexual functioning, loss of libido, and erectile dysfunction.

7. Fear of infecting others, particularly lovers, and fear of being infected by them.

8. Concern about the lover, and how he can cope.

9. Fear of being deserted and of dying alone.

10. Fear of dying in pain and discomfort.

11. Social, domestic, and occupational disruption.

Established lovers of patients with AIDS:

1. Fear about the possible death of the lover, grief, shock, and helplessness.

2. Fear of becoming infected, leading to anxiety, depression, and obsessional worries.

3. Reduced sexual functioning, specially loss of libido and loss of prospect of future sexual activity.

4. Guilt about the possibility of having infected the partner and others.

5. Uncertainty about what to do next; conflict between avoiding infection and love of the partner; guilt about this conflict.

6. Uncertainty about what to do to help the partner.

7. Clinical anxiety and depression.

Patients with HTLV-III, patients with PGL, and those fearing AIDS:

1. Anxiety about having AIDS or the virus.

2. Depression about the perceived inevitability of infection or developing the full syndrome or both.

3. Morbid obsession about the disease, ruminations, and checking for symptoms.

4. Guilt about being homosexual and the resurrection of past "misdemeanours".

5. Social, domestic, and occupational disruption and stress.

HTLV-III = human T lymphotropic virus type III

$\mathrm{PGL}=$ persistent generalised lymphodenopathy.

the syndrome should eventually prove fatal, he still has time left and needs to be helped to make the most of this. When the shock of diagnosis and its implications has been at least partly accommodated, he needs to be encouraged to take actions in areas where he can have control and not to simply give up, which would lead to feelings of helplessness and depression. It is worth agreeing with the patient a plan of tasks to be done. This needs to include putting his personal and financial affairs in order. Patients often need to make a will, they may be in partnership with others and need to settle tax and other issues. Naturally, whatever life plans are made will differ with the individual, but they must be his plans. These plans have to take realistic account of the patient's physical state and the probable course of the syndrome.

After the initial stage of getting the patient to make plans and to regain control over his life, he is likely to need continuing support. This can often be best achieved in a group with other sufferers, as they share a certain number of common problems. From time to time, however, men will also need individual sessions for help with particular problems. 
Counselling the established lovers of patients with AIDS

The diagnosis of AIDS is a severe blow to the established lover of the patient. The probable death of an established homosexual lover has just as much impact as the loss of a spouse or partner in heterosexual relationships. Additionally, the possibility of having been infected with the virus brings the potential of his own illness and death into sharp focus. The practical issues of coping with a dying partner, with his reduced emotional and physical capacities, and the consequences for both of them in social, emotional, sexual, work, and domestic terms are considerable. In short, the diagnosis creates as much of an upheaval for their lovers as for the patients.

Being cast in the role of care taker, sometimes when ill equipped or prepared for it, often creates new responsibilities and burdens. The lover may find himself acting as mediator between the patient, his friends, and health professionals, thus facing emotional and social tensions on all sides. Like the patient, the lover cannot escape the diagnosis, which comes to overshadow all aspects of his life. Waiting for the "final blow" is a particular strain. Lovers of patients with AIDS often have mixed feelings towards them. This adds to their burden because they feel guilty about not feeling entirely positive about their partner. The counsellor needs to raise this issue with the lovers if they do not raise it themselves. It is a great relief to lovers to know that these feelings are universal and quite natural.

As with patients, the lovers must be advised to adjust their sexual practices in order to minimise risk to themselves and their partner (see table I). Fidelity at this time is crucial, though this issue may not arise for some time after diagnosis as libido is often adversely affected initially. It must be clear to them that exposure to sexually transmitted diseases as well as other infections after being exposed to the virus may activate the syndrome. In any case there is a risk that the lover may pass on the virus to others, and he also needs to be regularly screened so that opportunistic infections may be treated as early as possible.

\section{Counselling men with PGL or who are HTLV-III positive}

Men with PGL or positive results for HTLV-III are often left "playing a waiting game", during which time they are regularly screened for possible further diagnostic signs. Many people in this category appear to adopt a fatalistic view of the future: "If it happens, it happens-there's nothing much to be done about it". Others respond with high levels of anxiety and, sometimes, depression. Still others take positive steps, including establishing contingencies in the advent of a possible later diagnosis of AIDS.

Again, the provision of psychological counselling to deal with the issues mentioned in table $I$ is often of great benefit in avoiding a panic or depressive reaction, and in keeping understandable anxieties to a minimum. The provision of as much information as can be given is important, particularly to ensure that patients with PGL and HTLV-III change their sexual behaviour (see table I). If patients do not understand why they should make changes in their sexual behaviour they will not do so. It needs to be stressed that the changes are for their benefit as much as for that of potential partners. Some patients take the view that if they restrict their sexual partners to those who are known to be positive for the virus there will be no problem. Besides there being uncertainties about whether this is a realistic approach to the virus itself, this puts them at risk of contracting other sexually transmitted diseases. It is important to make this point clearly. Many homosexual men have fairly extensive histories of STD and have become somewhat blasé about them. This view needs to be corrected.

Another common problem with men in these two groups is getting them to keep in contact with their doctor. Clearly, attending the clinic for follow up is unpleasant. At any visit they may well hear that they have AIDS, and if they do hear this there is nothing that can be done to halt the syndrome. Clearly the infected man is putting himself through considerable anxiety for what may appear to be little return. On the other hand it must be emphasised that prompt treatment of opportunistic infections is important when possible. It is also important to stress that when a man attends a clinic he may receive the reassurance that he probably does not have AIDS. Clinic attendance thus provides some sort of safety signal that has value in itself.

Acquiring PGL or being told that one is HTLV-III positive often serve as a catalyst for the ventilation of previously unmentioned and troubling emotional issues within stable relationships. The psychologist must be alert for potentially destructive themes arising in this manner. Many patients have reacted to diagnosis by completely re-evaluating their lives and activities. When a new perspective is adopted in this context, the social and sexual consequences of such adjustments may have to be carefully examined in a supportive and realistic way. Helping a patient accommodate the new status of "patient at risk" while maintaining constructive control over his life is important in such counselling. This is particularly a problem in the sexual area. Many men react parti- 
cularly badly to the sudden restriction in their sexual opportunities, and this needs careful support.

\section{Counselling men with fears of AIDS}

Far more common than AIDS itself is the fear of AIDS, which is encountered in a whole range of people, from the highly sexually active man who is objectively concerned to reduce his risk of contracting the syndrome, to the man who becomes clinically depressed and anxious about AIDS. ${ }^{9}$ Men in the latter category are sometimes hypochondriacal personalities for whom AIDS is simply a focus for general health worries, although by no means all such cases fall into this category. It is particularly unfortunate that the symptoms of anxiety and depression, weight loss, poor sleep, night fevers, and a feeling of lethargy are very similar to the early stages of AIDS itself. The impossibility of giving absolute assurances that the patient does not have AIDS is an added complication.

Whatever the level of the problem, the first task is to present clear information about the actual degree of risk and the steps that can be taken to reduce it. ${ }^{10}$ At present the risk of contracting AIDS appears to be relatively low in the United Kingdom, though this is likely to change. Table I provides suggestions for reducing risks. These suggestions should be emphasised to patients, with clear explanations about why they are desirable.

Simply providing information and reassurance will be sufficient for most homosexual men. For the particularly anxious man, however, this may not be enough. Initially he will need the opportunity to talk through his fears in detail. Specific anxiety management techniques may need to be applied in much the same way as they are applied to other fears and phobias. In some cases this will not prove enough, however, and it may be necessary to resort to medication and even psychiatric admission in severe cases. ${ }^{9}$

\section{Counselling comments}

Discussion throughout this paper has emphasised the need for appreciable changes in sexual lifestyles in all groups as a preventative or precautionary measure. Men with, and those most at risk of, AIDS are usually accustomed to large numbers of sexual partners, and the imperatives from within the homosexual community to maintain these levels of activity can be very strong. It is perhaps not surprising, therefore, that some reactions to the diagnosis or to the knowledge of having been exposed to the virus include unmodified or even increased levels of sexual activity (many, of course, react in the opposite way). The sheer extent of modification of sexual behaviour advocated, (including no anal or orogenital sexual activity, and avoiding "wet" kissing) simply adds to the problems of gaining full compliance. For this reason the guidelines in table I are explained as giving maximum avoidance of risk in high risk groups, and any degree of compromise adds to the possibility of exposure to the HTLV-III virus, sexually transmitted infections, and their potential consequences. The decision rests, of course, with the patient. This creates a need for consistent advice to be given by all health professionals on reducing numbers of sexual partners, in the hope that a consistent reaction minimising the risk to others will result.

Another important consideration in counselling patients and their lovers is the varying problems that arise as the condition progresses. The course of AIDS is unpredictable, requiring much resiliance from both affected parties as crises come and, it is hoped, go. Counselling must include an awareness of this progressive uncertainty, and the effects on psychological adjustment over time.

Many men are apparently advocating the use of condoms as protection from infection in anal intercourse. Although preventative measures of any kind are encouraged, the high failure rate with condoms in anal penetration makes for false optimism, and could ultimately prove detrimental in effective health education. Perhaps when more resiliant devices are available, this course may be advocated as a means of reducing direct risks, thus increasing the use of mechanical preventative measures and reducing the need for such stringent alterations in behaviour.

\section{Conclusion}

AIDS related counselling is a time consuming and difficult undertaking, often producing extreme distress in whole families. With the present rate of growth in numbers of reported cases in the United Kingdom, the demand for such intervention can be expected to grow. The need for wider preventative education in homosexual populations is more apparent than ever, in view of the wide spread of the AIDS virus. Counselling agencies in the United States have had a great deal of experience in dealing with the problem of counselling patients with AIDS. " Many agencies provide self help groups set up by patients with AIDS and their relatives, or by homosexual men's health centres. It is clear that these services are beneficial in providing essential support, information, and reassurance.

The small number of cases of AIDS in the United Kingdom makes self help groups more difficult to organise than in the United States, which has 
integrated homosexual communities in, for instance, New York and San Francisco. Encouraging moves towards the provision of such services for patients with AIDS and their families have, however, recently been made in England by, for instance, the Terence Higgins Trust.

We thank Mr George Leach, Dr Stephen Clift, and Dr Jon Weber for their helpful comments in the preparation of this paper.

\section{References}

1. Cahill KM, ed. The AIDS Epidemic. London: Hutchinson, 1984.

2. Safai B, Sarngadharan MG, Groopman JE, et al. Seroepidemiological studies of human T-lymphotropic retrovirus type III in acquired immunodeficiency syndrome. Lancet 1984; $\mathrm{i}$ : 1438-40.
3. Vilmer E, Barre-Sinoussi F, Rouzioux $C$, et al. Isolation of new lymphotropic retrovirus from two siblings with haemophilia B, one with AIDS. Lancet 1984; i:753-7.

4. Cheingsong-Popov R, Weiss RA, Dalgleish A, et at. Prevalence of antibody to human T-lymphotropic virus type III in AIDS and AIDS-risk patients in Britain. Lancet 1984; ii: 477-80.

5. Weinberg MS, Williams CJ. Male homosexuals: their problems and adaptation. New York: Oxford University Press, 1974.

6. Jaffe HW, Choi K, Thomas PA, et al. National case-control study of Kaposi's sarcoma and Pneumocystis carinii pneumonia in homosexual men: part 1, epidemiological results. Ann Intern Med 1983;99:145-51.

7. Fluker JL. Homosexuality and sexually transmitted diseases. Br J Hosp Med 1981;26:265-9.

8. Kubler-Ross E. On Death and Dying. London: Tavistock Publications, 1969.

9. Miller D, Green J, Farmer R, Carroll G. A 'pseudo-AIDS' syndrome following from a fear of AIDS. Br J Psychiatry 1985; 146: 550-1.

10. Miller D, Green J. The AIDS epidemic: advising homosexual men on reducing their level of risk. British Journal of Sexual Medicine 1984; 11: 106-8.

11. Anomymous. Community Education Handbook. New York: Gay Men's Health Crisis, 1984. 